Article

\title{
Sustainability Assessment of a Qingyuan Mushroom Culture System Based on Emergy
}

\author{
Xingguo Gu ${ }^{1,2,3}$, Qixian Lai ${ }^{1,2,3, *}$, Moucheng Liu ${ }^{4, *}$, Ziqun He ${ }^{1,2,3}$, Qingyang Zhang ${ }^{5}$ and \\ Qingwen Min ${ }^{4}$ \\ 1 Institute of Rural Development, Zhejiang Academy of Agricultural Sciences, No. 298, Middle Desheng Road, \\ Jianggan District, Hangzhou 310021, China \\ 2 Key Laboratory of Creative Agriculture, Ministry of Agriculture and Rural Affairs, China, No. 298, \\ Middle Desheng Road, Jianggan District, Hangzhou 310021, China \\ 3 Creative Agricultural Engineering Technology Research Center, Zhejiang, No. 298, Middle Desheng Road, \\ Jianggan District, Hangzhou 310021, China \\ 4 Institute of Geographic Sciences and Natural Resources Research, Chinese Academy of Sciences, No. 11A, \\ Datun Road, Chaoyang District, Beijing 100101, China \\ 5 Qingyuan Scientific Research Center of Edible Fungi, No. 138, Xinjian Road, Qingyuan County, \\ Lishui 310021, China \\ * $\quad$ Correspondence: laiqx@zaas.ac.cn (Q.L.); liumc@igsnrr.ac.cn (M.L.); Tel./Fax: +86-571-8640-4261 (Q.L.); \\ +86-10-6488-8202 (M.L.)
}

Received: 31 July 2019; Accepted: 3 September 2019; Published: 5 September 2019

\begin{abstract}
The Qingyuan mushroom culture system (QMCS) in Zhejiang Province has been recognized as the source of the world's first artificial cultivation of mushrooms with a history of more than 800 years. The system embodies the farming wisdom of the local people who have adapted themselves to and utilized nature and has integrated the traditional bark hacking method with multiple modern patterns for mushroom cultivation based on artificial microbial strains. We have investigated the input-output operation of farmers and assessed and analyzed emergy indicators in a bid to reflect and compare their economic and ecological benefits, as well as their sustainable development by analyzing the three typical mushroom cultivation patterns. The cost-benefit analysis of the three patterns shows that the sawdust medium-cultivated method (SMCM) is characterized by dominance in both net income without labor cost and labor productivity; while the evaluation based on emergy indicators has proven that each has its own advantages and disadvantages in terms of ecological and economic benefits and sustainable development. Among them, the bark hacking method (BHM) features the highest utilization rates of local and renewable resources, the smallest damage to the environment, the lowest production efficiency, and the highest exchange efficiency, but the sawdust medium-cultivated method is just the opposite, and the log-cultivated method (LCM) is the most favorable one for sustainable development. As its agricultural heritage, the QMCS' core of dynamic protection and adaptive management lies in enhancing the sustainable development of its agricultural production methods. It is recommended that the three patterns be improved by targeting their respective shortcomings and at the same time, integrate their advantages to explore a new sustainable development pattern for mushroom cultivation.
\end{abstract}

Keywords: agricultural heritage systems; qingyuan mushroom culture system; bark hacking method; log-cultivated method; sawdust medium-cultivated method; emergy

\section{Introduction}

Fungi is of the most diverse organisms on earth and plays an important ecological and socio-economic role. Not only do they serve as an important food source for humans, but they also 
serve as a "bridge" between the earth and humans through decomposition and biological symbiosis. According to statistics, there are about 2300 species in edible fungi, of which only about 200 are cultivated [1]. A large number of historical data shows that mushroom cultivation technology originated in China. During the Southern Song Dynasty, Wu Sangong (1130-1208) invented the first artificial method of mushroom cultivation in Longyan Village, Qingyuan County in Zhejiang Province, the bark hacking method (BHM) [2], which used natural spores to cultivate mushrooms on wood, marking the beginning of the composite utilization of forest fungi. For more than 800 years, this traditional method of mushroom cultivation has been inherited and developed in the area, including Qingyuan, Longquan City, and Jingning County. An agricultural heritage system composed of forest sustainable management, under forest industry development, mushroom cultivation and processing methods, and mushroom culture and folk customs has emerged [3]. In 2014, Qingyuan succeeded in applying for the second batch of Nationally Important Agricultural Heritage systems of China (China-NIAHS) with its Qingyuan mushroom culture system (QMCS) in Zhejiang [4,5], marking the first of China-NIAHS based on edible fungi. In addition, it is proactively applying for the Globally Important Agricultural Heritage Systems (GIAHS) [6,7].

Traditional mushroom cultivation is based on the management of forest resources and emphasizes the compound management of forest fungi [8], representing a model for the rational use of natural resources in earlier agricultural development. However, the requirements for forest species and topographic climate are demanding, and the labor environment is also relatively harsh. Since the creation of artificial strain technology in the 1930s, artificial methods for mushroom cultivation have been continuously improved and updated, and patterns, such as the log-cultivated method (LCM), sawdust medium-cultivated method (SMCM), and briquette cultivation method, have continued to emerge and have greatly impacted the traditional areas of mushroom production. The yield of mushroom can be greatly improved by the LCM and the SMCM, which provides convenience for scientific management and mechanized operation. These new patterns are inherited from the traditional BHM and incorporate more modern science and technology, providing a variety of options for local mushroom farmers to improve their income and labor environment. According to statistics, in the past 20 years, the annual mushroom output in Qingyuan has remained at about 5000 tons, of which more than $95 \%$ is cultivated by the SMCM and only a few tons by the LCM and the BHM. So, what are the advantages of the modern cultivation patterns compared to the traditional one? Do modern patterns meet the objectives of regional sustainable development? How can the sustainability of the traditional QMCS be improved? These issues are of great concern to the protection and inheritance of agricultural heritage systems [9], and also have a great impact on the sustainable development of the Qingyuan area.

To solve the above issues, it is necessary to evaluate and analyze the various cultivation patterns in terms of the economy and the ecology of the heritage sites to reflect the status quo of the sustainable development of the QMCS. At present, the relevant literature studies the evolution, production methods and combined utilization of different mushroom cultivation patterns [10-12] in the main, providing a sound scientific foundation for understanding the historical characteristics of mushroom agricultural heritage and improving the production efficiency and management level of mushroom cultivation. However, it lacks a comprehensive study of mushroom cultivation based on sustainability. Emergy is a scientific concept and measurement scale developed from system ecology and ecological economics. It can convert the material flow, energy flow, and value stream of agricultural production systems into a unified standard, which is convenient for quantitative analysis and assessment of development sustainability [13]. In view of this, this study makes a systematic analysis and indicator assessment of the three typical cultivation methods, namely the BHM, LCM, and SMCM with the emergy methods to evaluate and compare their economic and ecological benefits, as well as their sustainable development, and to provide a sound scientific basis for the protection and development of the agricultural heritage system [14]. 


\section{Overview of the Study Area}

The QMCS in Zhejiang takes Qingyuan as the preservation area of the agricultural heritage system, which also serves as the study area for this paper. Qingyuan is located in the southwest of Zhejiang at $118^{\circ} 50^{\prime}-119^{\circ} 30^{\prime} \mathrm{E}$ and $27^{\circ} 25^{\prime}-27^{\circ} 51^{\prime} \mathrm{N}$. It dips from the northeast to the southwest geographically, with an altitude of 240 to $1856.7 \mathrm{~m}$, and consists of a variety of landforms including valley, basin, hill, and low and medium mountains. According to the Köppen-Geiger climate classification, it has a humid subtropical climate ( $\mathrm{Cfa}$ ) with a mean annual minimum temperature of $7.6^{\circ} \mathrm{C}$, a maximum temperature of $27.3^{\circ} \mathrm{C}$ and mean annual precipitation of $1760 \mathrm{~mm}$. The forest coverage rate is $86 \%$, and the common vegetation includes various types, such as coniferous forest, mixed coniferous and broad-leaved forest, bamboo forest, shrub, grass, and meadow. Thus, it is fairly rich in wild fungus resources, with nearly 423 large-scale fungi, including 360 kinds of edible (medicinal) fungi and 79 important valuable strains [15].

In 2018, the registered population of Qingyuan was 20,5100, and the per capita GDP was 51,910-yuan, accounting for 52.6\% of Zhejiang's and 80.5\% of China's per capita GDP [16-18]. The edible fungus industry focused on mushrooms is Qingyuan's traditional industry and its pillar of the agricultural industry. In 2002, the Qingyuan mushroom won the nationally protected product of origin, the first for a regional edible fungus brand in China. In recent years, the brand value of Qingyuan mushrooms has continued to grow, with products sold to major cities in China and more than 60 foreign countries and regions including Japan, Southeast Asia, Europe, and the United States.

\section{Data and Methods}

\subsection{Pattern Demarcation}

The three patterns of mushroom cultivation, the BHM, LCM, and SMCM, coexist in the preservation zone of the QMCS agricultural heritage system, with different production methods as well as input and output contents. According to relevant literature and field investigation, the study first demarcates the three patterns in terms of production characteristics and system structure (Table 1) [10]. The BHM is a method in which the farmers chop the suitable wood for mushroom cultivation in the mountain forest, using the natural spores to grow mushrooms on the bark. This production cycle is the longest but is also the basis for other artificial methods for mushroom cultivation. The LCM and SMCM use cut logs and wood pellets to grow mushrooms after the creation of artificial strains' production technology, featuring relatively shorter production cycles and a higher degree of artificialization.

Table 1. Basic characteristics of the three mushroom cultivation patterns in Qingyuan.

\begin{tabular}{cccccc}
\hline $\begin{array}{c}\text { Mushroom } \\
\text { Cultivation } \\
\text { Patterns }\end{array}$ & $\begin{array}{c}\text { Creation/Time } \\
\text { of Introduction }\end{array}$ & $\begin{array}{c}\text { Cultivating } \\
\text { Location }\end{array}$ & $\begin{array}{c}\text { Source of } \\
\text { Strains }\end{array}$ & $\begin{array}{c}\text { Cultivation } \\
\text { Material }\end{array}$ & $\begin{array}{c}\text { Production } \\
\text { Cycle }\end{array}$ \\
\hline BHM & $\begin{array}{c}\text { in the early 12th } \\
\text { century }\end{array}$ & $\begin{array}{c}\text { mountain } \\
\text { forest }\end{array}$ & $\begin{array}{c}\text { natural } \\
\text { dispersion } \\
\text { distributed }\end{array}$ & $\begin{array}{c}\text { wood for } \\
\text { mushroom } \\
\text { cultivation }\end{array}$ & $\begin{array}{c}\text { five to eight } \\
\text { years }\end{array}$ \\
\hline LCM & $1970 \mathrm{~s}$ & $\begin{array}{c}\text { wood/lath } \\
\text { house }\end{array}$ & $\begin{array}{c}\text { artificial } \\
\text { cultivation }\end{array}$ & $\begin{array}{c}\text { cut log for } \\
\text { mushroom } \\
\text { cultivation }\end{array}$ & $\begin{array}{c}\text { three to five } \\
\text { years }\end{array}$ \\
\hline SMCM & $1980 \mathrm{~s}$ & $\begin{array}{c}\text { mushroom } \\
\text { house }\end{array}$ & $\begin{array}{c}\text { artificial } \\
\text { cultivation }\end{array}$ & wood pellets & one year \\
\hline
\end{tabular}


Figures 1 and 2 show the system structure of the three patterns of mushroom cultivation [19]. The mushroom cultivation system is linked to the outside world through resource input and product output. The input resources can be divided into four categories: renewable and non-renewable resources from the natural environment, and renewable and non-renewable resources from economic and social feedback [20]. Solar energy, wind energy, and rainwater are the renewable resources from the natural environment common to the three mushroom cultivation patterns. Compared to the BHM, the LCM and SMCM use more resources from human economic and social feedback, the resource input of which is elaborated in 4.1. In terms of output, the three patterns focus on mushrooms, and the proceeds from their sales can be used to purchase resources from human economic and social feedback. In the mushroom cultivation system, the BHM uses mushroom wood and spores from nature to cultivate mushrooms, combining forest management with the utilization of strains; while the LCM and SMCM use artificial strains to cultivate mushrooms on wood and wood pellets, which have incorporated more artificial technology.

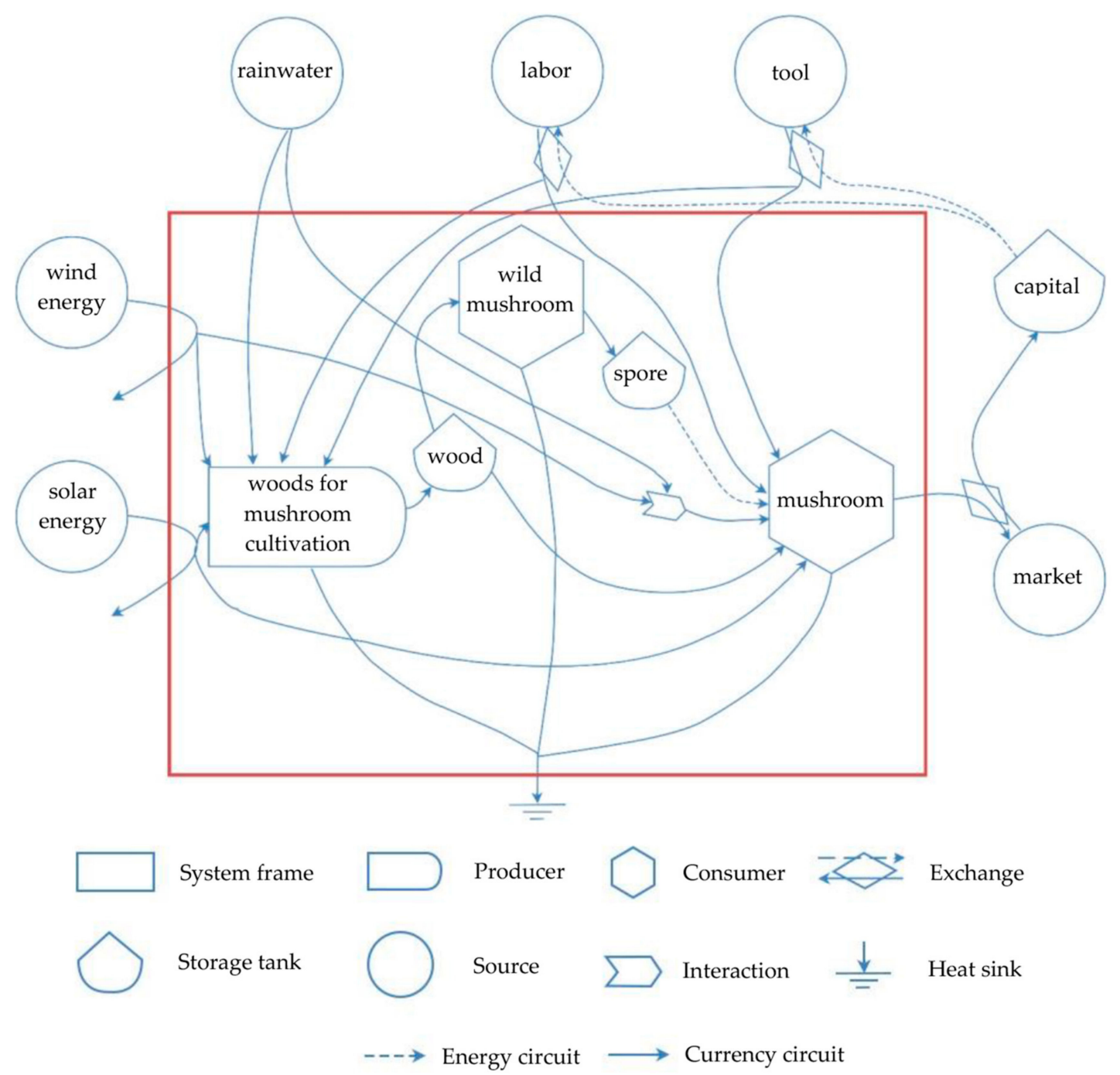

Figure 1. A schematic diagram showing the pattern structure of mushroom cultivation. 


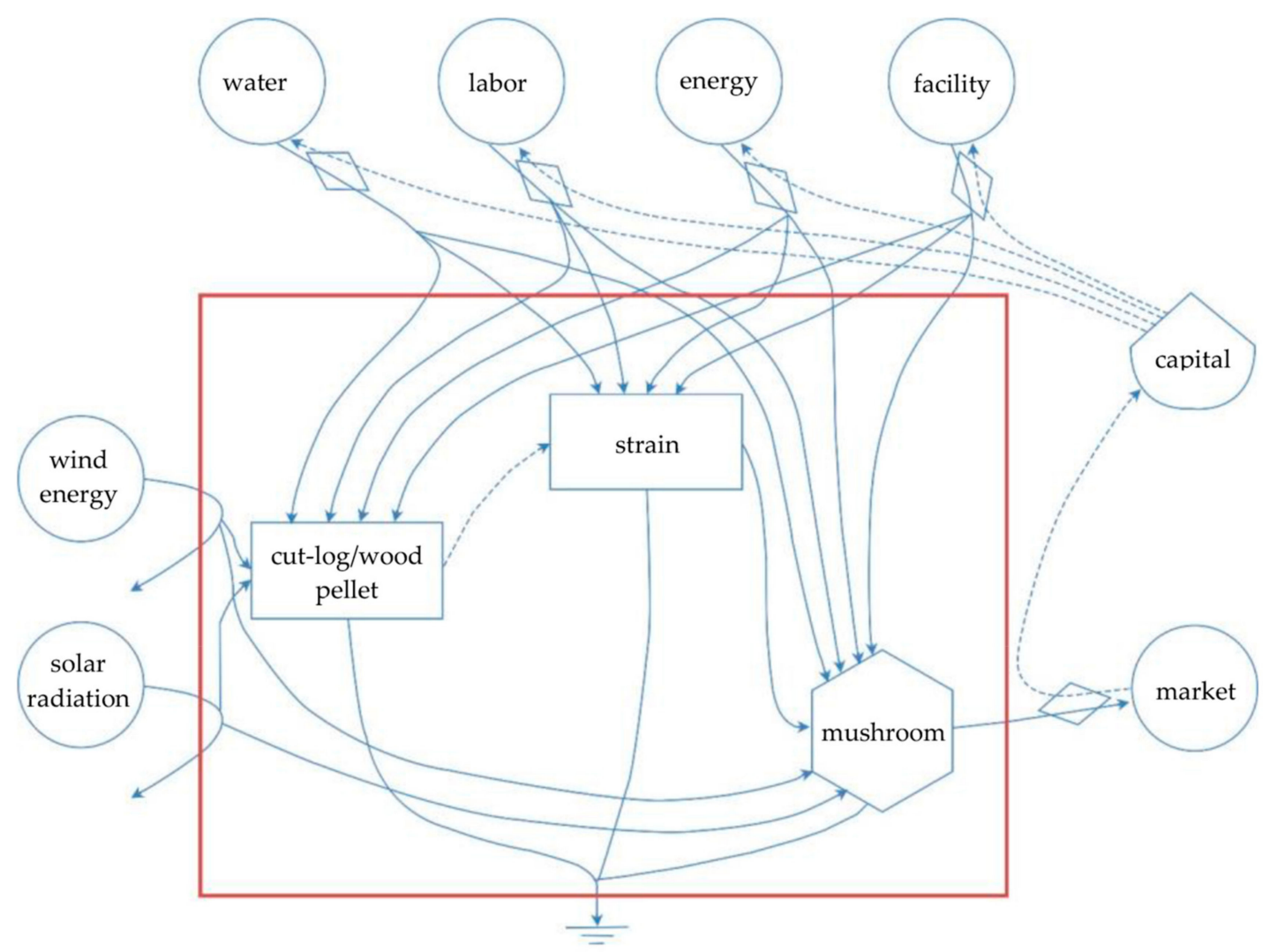

Figure 2. A schematic diagram showing the bark hacking method/sawdust medium-cultivated method (BHM/SMCM) pattern structure of mushroom cultivation. The legend of Figure 2 is the same as Figure 1.

\subsection{Data Sources}

In August and November 2018, we went to Qingyuan to conduct pre-study and official investigations on the input and output of the three patterns of mushroom cultivation. During the pre-study investigation stage, we gathered basic information on the different patterns, including distribution areas, cultivation material, seasonal arrangements, management procedures, through interviews with relevant departments and farmers; thereby, the scheme for an official investigation and the survey questionnaire of farmers were determined accordingly. The survey questionnaire was composed of two parts: input and output. The investigation for the former usually included the types, quantities, and prices of the necessary land, strains, nutrients, facilities, tools, labor, energy, and medicine required for the production of mushrooms, while the survey of the latter was about the yield and price of mushrooms in the main. As part of the official investigation, a questionnaire survey of farmers was conducted on the principle of random sampling to get the details of the input and output of mushroom production. Currently, most of the mushrooms are produced by the SMCM within the preserved area, while only a few mushroom farmers still produced through the LCM and BHM. The questionnaire survey on the BHM pattern of mushroom cultivation was carried out mainly in its place of origin, Longyan Village, and less so in other areas. Since the log cultivated pattern of mushroom cultivation is relatively scattered, we visited Longyan, Qiaomo, and Huangpi villages with the questionnaire survey. The SMCS of mushroom cultivation is distributed throughout the county, with the questionnaire placing great emphasis on the concentrated areas of Zhoudun, Damaowan, Wudu, Cai Duan, and Huangninong villages. A total of 90 questionnaires were distributed (BHM-20, LCM-30, and SMCM-40), with valid questionnaires of over 60\% were collected (BHM-13, LCM-24, and SMCM-31). 


\subsection{Research Methods}

\subsubsection{Emergy Analysis Procedures}

The emergy theory was originally based on traditional energy analysis, emphasizing the difference in energy levels and providing a uniform measure of the energy of different qualities. Emergy is defined as the total amount of available energy needed directly or indirectly to generate a product or service [13]. Considering solar energy is the original form of all energy, it is commonly used as one equivalent to quantify other forms of energy and expressed as solar emjoules, abbreviated as sej. The amount of emergy needed to generate one unit of product or service is defined as unit emergy values (UEVs) and expressed with the unit of sej/unit. The main steps of conducting emergy analysis on one integrated economic-ecological system are usually synthesized as follows: first, identifying the boundary of the system and collecting basic data including the type, quantity, and value of the input resources and output products; second, classifying the aforementioned flows and converting the material, energy, value, etc., in the system into a unified metric, the emergy, through the unit emergy values (UEVs) and the emergy/money ratio (EMR); finally, selecting some emergy indicators that can reflect the structure, function, and ecological and economic benefits of the system to evaluate its sustainability performance and support relevant decisions [21].

\subsubsection{UEVs and EMR}

The emergy baseline is the benchmark for calculating the various UEVs within the Earth. Thus, it is supposed to be pre-determined when calculating the UEVs. Since H.T. Odum (1996) first calculated the emergy baseline $(9.44 \times 1024 \mathrm{sej} /$ year $)$ [13], other scholars have updated it three times, namely to $15.83 \times 1024 \mathrm{sej} /$ year [22], $15.20 \times 1024 \mathrm{sej} /$ year [23], $12.00 \times 1024 \mathrm{sej} /$ year [24]. H.T. Odum believed that the emergy analysis should be based on the new emergy baselines. Therefore, the emergy baseline of this study is $12.00 \times 1024$ sej/year. Since the energy of the ecological-economic system on the Earth comes from the sun, the emergy of other energy in the system can be converted by solar emergy, and its UEV can be defined as $1 \mathrm{sej} / \mathrm{J}$. Furthermore, both domestic and foreign scholars have used a variety of methods to calculate the UEVs of wind energy, rain energy, labor, electric energy, edible fungi, etc. The study draws on previous research results and was adjusted according to the emergy baseline (Table 2). In addition, although there are no UEVs for the strains, facilities, tools, etc., their EMR can be obtained through investigation. Afterward, the EMR for the ecological-economic system of Lishui City (the total emergy/year GDP, the unit: sej/¥) can be applied to calculate its emergy. According to the statistical energy conversion coefficient and UEVs $[13,20,25-33]$ in Lishui's statistics and literature, its total emergy in 2017 was $8.95 \times 1022$ sej, which has led to an EMR of $7.45 \times 1011$ sej/yuan for the region's system.

Table 2. Solar unit emergy values (UEVs) of related substances and energy.

\begin{tabular}{ccccc}
\hline Item & Unit & UEVs (sej/unit) & Data Source & $\begin{array}{c}\text { Adjustment } \\
\text { Coefficient }\end{array}$ \\
\hline Solar energy & $\mathrm{J}$ & 1.00 & Definition & 1.00 \\
Wind energy & $\mathrm{J}$ & $1.05 \times 10^{4}$ & Odum, 1996 & 1.27 \\
Chemical energy of rainwater & $\mathrm{J}$ & $1.82 \times 10^{4}$ & Odum, 1996 & 1.27 \\
Potential energy of rainwater & $\mathrm{J}$ & $1.05 \times 10^{4}$ & Odum, 1996 & 1.27 \\
Wood for mushroom cultivation & $\mathrm{J}$ & $3.49 \times 10^{4}$ & Yan Maochao, 2001 & 1.27 \\
Wood pellets & $\mathrm{g}$ & $5.48 \times 10^{8}$ & Calculated by wood & 1.00 \\
Running water & $\mathrm{g}$ & $9.10 \times 10^{4}$ & Lan Shengfang et al., 2002 & 1.27 \\
Aerosol disinfectant & $\mathrm{g}$ & $1.60 \times 10^{10}$ & Lan Shengfang et al., 2002 & 1.27 \\
Labor & $\mathrm{J}$ & $7.38 \times 10^{6}$ & Rosa et al., 2008 & 0.76 \\
Charcoal & $\mathrm{J}$ & $1.06 \times 10^{4}$ & Lan Shengfang et al., 2002 & 1.27 \\
Electric energy & $\mathrm{J}$ & $1.60 \times 10^{5}$ & Lan Shengfang et al., 2002 & 1.27 \\
Dried mushrooms & $\mathrm{J}$ & $5.68 \times 10^{5}$ & Mao Wei, 2008 & 1.27 \\
\hline
\end{tabular}




\subsubsection{Emergy Indicators}

According to the requirements of the study, we have chosen five indicators to comprehensively analyze and assess the ecological and economic benefits, as well as the development sustainability of the system. They are emergy self-support ratio (ESR), environmental load ratio (ELR), emergy yield ratio (EYR), emergy exchange ratio (EER), and emergy sustainable indices (ESI) [34,35]. The relevant formulas and their meanings are shown in Table 3.

Table 3. Emergy indicators and their calculation methods.

\begin{tabular}{|c|c|c|c|}
\hline Standard & Indicator & Formula & Meaning \\
\hline \multirow{2}{*}{ Ecology } & ESR & $(\mathrm{IR}+\mathrm{IN}) / \mathrm{I}$ & To evaluate the support ability of the natural environment \\
\hline & ELR & $(\mathrm{IN}+\mathrm{FN}) /(\mathrm{IR}+\mathrm{FR})$ & To evaluate the load level of the natural environment \\
\hline \multirow{2}{*}{ Economy } & EYR & $\mathrm{Y} /(\mathrm{FR}+\mathrm{FN})$ & To evaluate the yield ratio of economic events \\
\hline & EER & $\mathrm{M} \cdot \mathrm{EMR} / \mathrm{Y}$ & To reflect the benefits of system yield in marketing \\
\hline Sustainability & ESI & EYR/ELR & $\begin{array}{l}\text { To comprehensively measure the development } \\
\text { sustainability of the system }\end{array}$ \\
\hline
\end{tabular}

Note: IR is the emergy of renewable resources from the natural environment, IN is the emergy of non-renewable resources from the natural environment, FR is the appreciation of renewable resources from economic and social feedback, and FN is the appreciation of non-renewable resources from economic and social feedback. I is the emergy of the total input, $\mathrm{Y}$ is the appreciation of the total output, and $\mathrm{M}$ is the emergy of the total sales of the output in the market.

\section{Results and Analysis}

\subsection{Value Stream Analysis}

According to the questionnaire survey of farmers, the input and output data of the three mushroom cultivation systems were summarized and classified and then calculated according to their monetary value. The results are shown in Table 4 . The items invested in the cultivation of mushrooms mainly include land, strains, fungi, facilities, tools, labor, and energy, with even a certain amount of disinfectant and tap water needed in the SMCM. The highest input for the BHM, LCM, and SMCM is labor, accounting for $81.28 \%, 70.78 \%$, and $42.01 \%$, respectively; followed by fungous materials, accounting for $10.27 \%, 11.06 \%$, and $39.42 \%$, respectively. The sum of the two exceeds $80 \%$, indicating that the inputs of the three patterns are mainly labor and fungous materials. Furthermore, the labor cost of the BHM is relatively the highest, but the proportion of the fungus cost is the lowest; meanwhile, the SMCM is just the opposite. According to the formation time of the three patterns, the change in the cost ratio of the major input items for mushroom production is closely related to the progress of human technology. In modern production, the proportion of labor input has been greatly reduced, but fungous material processing has gone deeper, so the cost ratio of fungous materials has also increased accordingly. In addition, the land value is null for BHM because the wood for mushroom cultivation is scattered in the mountain forest, which is a public good. As for output, both the BHM and LCM will produce mushrooms, and the fungus materials will return to the natural environment after being fully utilized; but, in addition to mushrooms, the waste bags in the SMCM can also be recycled, so their market value should also be included in the total revenue.

The preceding data may be applied to develop a cost-benefit analysis. The net revenue equals the total revenue with the deduction of all input costs. Figure 3 shows that, unlike the BHM and LCM, the net revenue of the SMCM is negative, indicating that the total revenue of this pattern is less than its total costs. According to the Assumptions of Economic Rationality, it is reasonable to use the BHM and LCM since the total revenue of mushroom cultivation by these two methods exceeds the total costs. The question is why the SMCM is still popular among mushroom-cultivating farmers when its economic profit is negative. Let us look back at Table 4, the total cost-labor cost of the SMCM is much smaller than its total revenue, that is, in ignoring the labor cost, the net revenue of the SMCM is the highest. However, the survey found that most farmers would ignore their own labor cost when 
calculating economic income, regarding it as their labor income, so that is why they choose the SMCM for mushroom cultivation.

Table 4. Costs, benefits, and ratios of the three patterns of mushroom cultivation.

\begin{tabular}{ccccccc}
\hline \multirow{2}{*}{ Item } & \multicolumn{2}{c}{ BHM } & \multicolumn{2}{c}{ LCM } & \multicolumn{2}{c}{ SMCM } \\
\cline { 2 - 7 } & $\begin{array}{c}\text { Value } \\
\text { (yuan) }\end{array}$ & $\begin{array}{c}\text { Proportion } \\
(\mathbf{\%})\end{array}$ & $\begin{array}{c}\text { Value } \\
\text { (yuan) }\end{array}$ & $\begin{array}{c}\text { Proportion } \\
\mathbf{( \% )}\end{array}$ & $\begin{array}{c}\text { Value } \\
\text { (yuan) }\end{array}$ & $\begin{array}{c}\text { Proportion } \\
(\mathbf{\%})\end{array}$ \\
\hline Land & 0 & 0.00 & 113 & 2.65 & 1800 & 1.87 \\
Strain & 0 & 0.00 & 438 & 10.32 & 1600 & 1.66 \\
Fungous materials & 76 & 10.27 & 469 & 11.06 & 38,000 & 39.42 \\
Facility & 0 & 0.00 & 0 & 0.00 & 11,067 & 11.48 \\
Tools & 37 & 4.94 & 169 & 3.98 & 2325 & 2.41 \\
Artificial & 600 & 81.28 & 3000 & 70.78 & 40,500 & 42.01 \\
Energy & 26 & 3.51 & 51 & 1.20 & 920 & 0.95 \\
Other & 0 & 0.00 & 0 & 0.00 & 195 & 0.20 \\
Total cost & 739 & & 4240 & & 96,407 & \\
Total cost-Labor cost & 139 & & 1240 & & 55,907 & 907 \\
Mushrooms (dried) & 960 & 100.00 & 6600 & 100.00 & 80,000 & 99.95 \\
Other & 0 & 0.00 & 0 & 0.00 & 40 & 0.05 \\
Total revenue & 960 & & 6600 & & 80,040 & \\
\hline
\end{tabular}

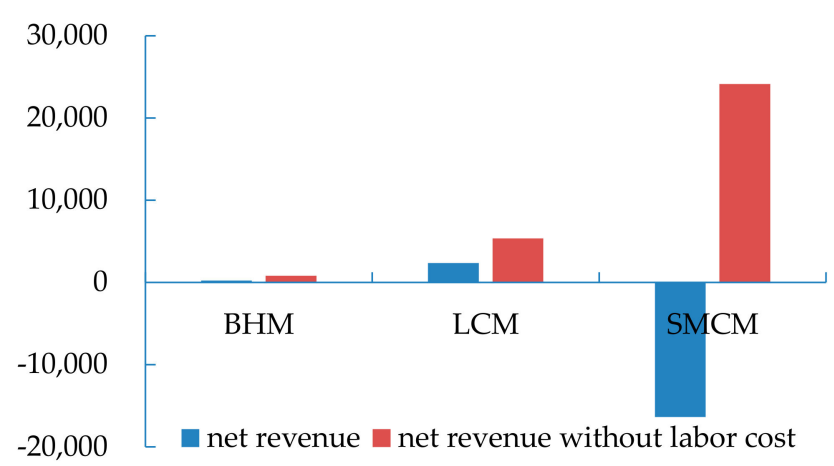

Figure 3. A plot showing the net income of the three patterns of mushroom cultivation.

Labor productivity is the economic benefit that labor produces in one year and is an important basis for farmers to choose their economic activity. It is calculated that the labor productivity of the LCM and SMCM are similar, and both are much higher than that of the BHM (Figure 4). This is mainly because the management of BHM cultivation is so extensive with lower output.

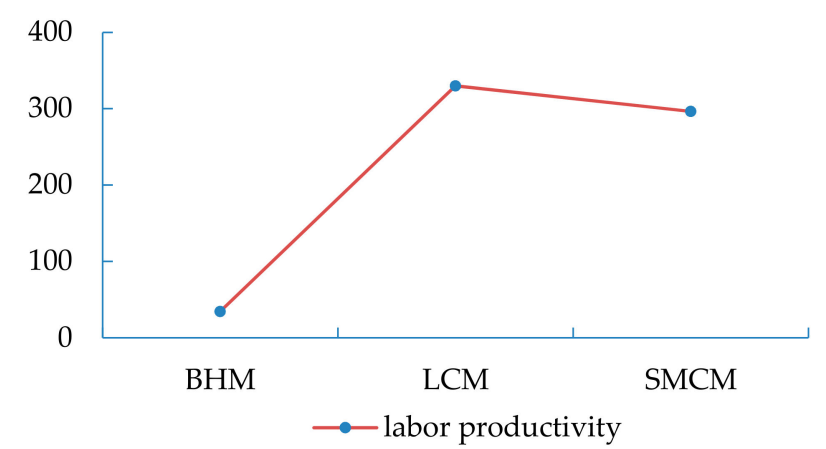

Figure 4. A plot showing the labor productivity of the three patterns of mushroom cultivation. 


\subsection{Emergy Stream Analysis}

According to the input and output of the three mushroom cultivation patterns, the study estimates their emergy stream using UEVs and EMR, summarizes resources of the same type in input, and calculates their proportion to total input emergy (Table 5). It can be seen that none of the three patterns use non-renewable resources from the natural environment. Thus, resources from the natural environment are all renewable. The proportion of BHM, LCM, and SMCM renewable resource emergy from the natural environment is $68.44 \%, 39.74 \%$, and $0.39 \%$, respectively, while the proportion from the economic society is $27.83 \%, 53.47 \%$, and $80.76 \%$, respectively, showing an opposite trend. The proportion of total renewable resource emergy is $96.26 \%, 93.21 \%$, and $81.15 \%$, respectively, much higher than those of the total non-renewable resource emergy. Moreover, the renewable resource utilization of the BHM created in the early 12th century is better than that of the modern LCM and SMCM.

Table 5. The relationship of emergy stream and proportions of input items.

\begin{tabular}{|c|c|c|c|c|c|c|}
\hline \multirow{2}{*}{ Item } & \multicolumn{2}{|c|}{ ВHМ } & \multicolumn{2}{|c|}{ LCM } & \multicolumn{2}{|c|}{ SMCM } \\
\hline & Emergy (sej) & $\begin{array}{l}\text { Proportion } \\
\quad(\%)\end{array}$ & Emergy (sej) & $\begin{array}{l}\text { Proportion } \\
(\%)\end{array}$ & Emergy (sej) & $\begin{array}{l}\text { Proportion } \\
\quad(\%)\end{array}$ \\
\hline $\begin{array}{l}\text { Renewable resources } \\
\text { from the natural } \\
\text { environment }\end{array}$ & $1.64 \times 10^{14}$ & 68.44 & $4.89 \times 10^{14}$ & 39.74 & $1.53 \times 10^{14}$ & 0.39 \\
\hline $\begin{array}{l}\text { Non-renewable } \\
\text { resources from the } \\
\text { natural environment }\end{array}$ & 0.00 & 0.00 & 0.00 & 0.00 & 0.00 & 0.00 \\
\hline $\begin{array}{l}\text { Renewable resources } \\
\text { from economic and } \\
\text { social feedback }\end{array}$ & $6.66 \times 10^{13}$ & 27.83 & $6.58 \times 10^{14}$ & 53.47 & $3.14 \times 10^{16}$ & 80.76 \\
\hline $\begin{array}{l}\text { Non-renewable } \\
\text { resources from } \\
\text { economic and social } \\
\text { feedback }\end{array}$ & $8.95 \times 10^{12}$ & 3.74 & $8.37 \times 10^{13}$ & 6.79 & $7.32 \times 10^{15}$ & 18.85 \\
\hline $\begin{array}{l}\text { Resources from the } \\
\text { natural environment }\end{array}$ & $1.64 \times 10^{14}$ & 68.44 & $4.89 \times 10^{14}$ & 39.74 & $1.53 \times 10^{14}$ & 0.39 \\
\hline $\begin{array}{l}\text { Resources from } \\
\text { economic and social } \\
\text { feedback }\end{array}$ & $7.56 \times 10^{13}$ & 31.56 & $7.42 \times 10^{14}$ & 60.26 & $3.87 \times 10^{16}$ & 99.61 \\
\hline Renewable resources & $2.31 \times 10^{14}$ & 96.26 & $1.15 \times 10^{15}$ & 93.21 & $3.15 \times 10^{16}$ & 81.15 \\
\hline $\begin{array}{l}\text { Non-renewable } \\
\text { resources }\end{array}$ & $8.95 \times 10^{12}$ & 3.74 & $8.37 \times 10^{13}$ & 6.79 & $7.32 \times 10^{15}$ & 18.85 \\
\hline Total input & $2.39 \times 10^{14}$ & 100.00 & $1.23 \times 10^{15}$ & 100.00 & $3.88 \times 10^{16}$ & 100.00 \\
\hline
\end{tabular}

The resources from the natural environment are generally locally sourced, while the resources from economic and social feedback are more mobile. The proportions of economic and social feedback resources for the BHM, LCM, and SMCM are $31.56 \%, 60.26 \%$, and $99.61 \%$, respectively, indicating that most of the input resource emergy in BHM mushroom production is from the local natural environment, more than half of the input resource emergy in the LCM comes from the economic society, while for the SMCM, the input emergy of industrial auxiliary resources is excessive, mainly depending on emergy purchase and greatly affected by the market.

\subsection{Evaluation and Analysis of Emergy Indicators}

According to the calculation formula, the ESR is in proportion to the resource emergy of the natural environment input/total input emergy ratio, reflecting the self-sufficiency ability of the system and the support ability of the natural environment. The order from large to small of the three patterns of mushroom cultivation in the ESR is the BHM, LCM, and SMCM (Figure 5), indicating that most of 
the resources for BHM rely on local support, with the strong support ability of the natural environment; while almost all the resource input of the SMCM comes from liquidity market resources, and the support ability of the natural environment is weak.

The ELR is the ratio between the non-renewable resource emergy and the renewable emergy of the input system, reflecting the impact of the system on the local environment. Since the non-renewable resource emergy from the natural environment in the three patterns of mushroom production is zero, all the non-renewable resource emergy of the input comes from the economic and social purchasing emergy, indicating that the primary cause of environmental pressure is the irrational use of non-local resources. Furthermore, the order of the three patterns from small to large in the ELR is the BHM, LCM, and SMCM, indicating that the BHM has the least impact on the environment and its ecological benefits are the highest, while the SMCM has the greatest impact on the environment, and its ecological benefits are the lowest.

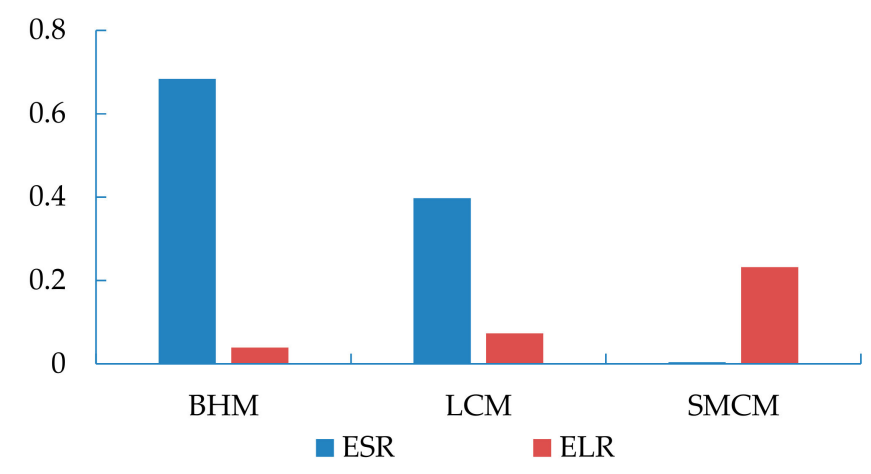

Figure 5. Ecological evaluation indicators in the natural environment.

The EYR and EER are two important emergy indicators for measuring the economic efficiency of the system. The former represents the ratio of the output emergy of the system to the emergy of the economic and social feedback resources, reflecting the production efficiency of the system; the latter is the ratio of the monetary emergy of the system's output to the emergy of the product itself, reflecting the exchange efficiency of the system. It can be seen from Figure 6 that the three mushroom cultivation patterns can be ranked from small to large as the BHM, LCM, and SMCM in terms of the EYR, indicating that the BHM is the lowest, while the SMCM is the highest in terms of production efficiency. The systems can be ranked from large to small as the BHM, LCM, and SMCM in terms of the EER, showing that the emergy yield of the BHM mushroom production is first in market transaction, which is directly related to the relatively higher market price thanks to its low yield and high quality. In contrast, mushrooms produced by the SMCM feature large supply volume, lower price, and the lowest EER in the market.

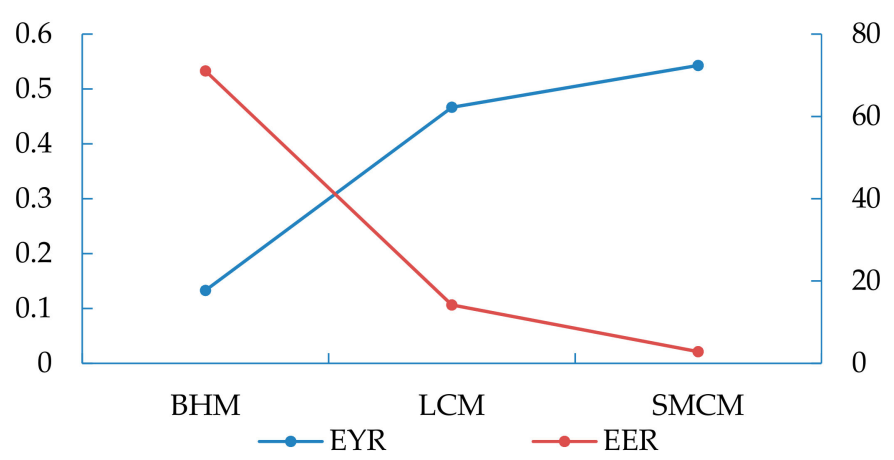

Figure 6. Results of economic and social evaluation indicators. 
The ESI is the ratio of the EYR to the ELR, indicating the ability to obtain both the expected yield and ecological environment protection, that is, the capacity for sustainable development. Figure 7 shows that the three patterns of mushroom cultivation can be ordered from small to large as the SMCM, BHM, and LCM in terms of the ESI. Although the SMCM has the highest EYR, its ELR is also the highest, indicating that the pattern is getting economic output at the expense of the ecological environment, so its sustainability is poor. The BHM has the lowest EYR and the lowest ELR, so it is necessary to improve its production efficiency by improving intensive management, thereby improving its sustainability. Finally, the LCM is characterized by moderate EYR and ELR, leaving room for improvement. It is a pattern of mushroom production currently worth promoting.

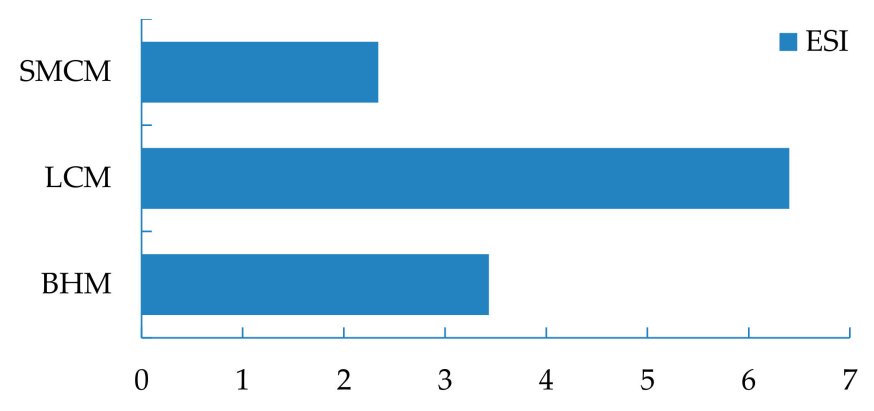

Figure 7. Calculation results of sustainability assessment indicators.

\section{Conclusions and Discussion}

The study analyzes and compares the economic benefits, ecological benefits, and sustainable development ability of three mushroom cultivation patterns in Qingyuan. The cost-benefit analysis directly shows that mushroom farmers often ignore their own labor cost when calculating net income, and regard it instead as their labor income, so the SMCM is advantageous both in terms of net income without labor cost and labor productivity, which is the immediate reason why it is the most commonly employed method among mushroom farmers.

The emergy analysis and evaluation of the three mushroom cultivation patterns reveal the essence of the issue in-depth. The research conclusion can be divided into three parts. First, through the calculation of the ESR and ELR, we have found that the BHM is characterized by the highest utilization rate of local land and renewable resources, the smallest impact on the environment, and thereby, has the highest ecological benefits. The SMCM is the opposite, having the lowest ecological benefits. Second, the EYR and EER reflect the production efficiency and exchange efficiency of the system, respectively. The results show that the BHM features the lowest production efficiency but the highest exchange efficiency, and the SMCM is the opposite. Third, combined with the comprehensive evaluation of the emergy indicators reflecting both ecological and economic benefits, we found that the LCM has the highest sustainable development ability, while the SMCM has the lowest. Therefore, the SMCM only has the highest production efficiency, while its ecological benefits and sustainable development capabilities are relatively lower. Although the LCM is not advantageous in terms of ecological and economic benefits, it suits the goals of regional sustainable development best.

As to the agricultural heritage, the core of the dynamic protection and adaptive management of Zhejiang QMCS lies in enhancing the sustainable development ability of its agricultural production patterns [36]. The analysis and evaluation of indicators based on emergy measurements can provide some support and reference for achieving this goal. The traditional BHM for mushroom cultivation is based on large-scale deforestation of mushroom forests, which is contrary to the current policy of closing hillsides for afforestation. Therefore, it is difficult to restore and promote this method, but the traditional knowledge and techniques it holds concerning forest conservation and utilization should be protected and passed on through concentrated presentation. The LCM has the highest ability for sustainable development, but its development is also constrained by the limited supply of wood 
resources for mushroom cultivation, which may be solved through artificial afforestation and market purchase. The main impediments for the SMCM lie in the high input of non-renewable resources and a greater impact on the environment. It is recommended that the sustainability of the pattern be upgraded by ecologically improving its means of production.

In all, the three patterns for mushroom cultivation are derived from the same line of technical principles, but with the advancement of science and technology and the progress of economic and social development, the mode of production has undergone major changes impacting the sustainability of the entire heritage system. In addition to the improvement of each mushroom cultivation pattern, we recommended combining their existing advantages and explore new forms of mushroom production with high sustainable development ability. It should be noted that in improving or creating new patterns of mushroom cultivation, it is necessary to coordinate the interests among the producers, consumers, governments, and scientific research institutions, to achieve multi-participation through benefit sharing and to promote the sustainability of QMCS.

Author Contributions: X.G., Q.L., and M.L. conceived and designed the research; X.G., Z.H., and Q.Z. collected and analyzed the data; Q.M. revised the paper. X.G. and M.L. wrote the paper together. All authors have read and approved the final manuscript.

Funding: This research was funded by the Science and Technique Plan of Zhejiang Province (2018C02057), and the International Exchange and Cooperation Project of Ministry of Agriculture of China "Conservation of Globally Important Agricultural Heritage Systems (GIAHS) in China in 2019".

Conflicts of Interest: The authors declare no conflict of interest.

\section{References}

1. Martínez-Ibarra, E.; Gómez-Martín, M.B.; Armesto-López, X.A. Climatic and Socioeconomic Aspects of Mushrooms: The Case of Spain. Sustainability 2019, 11, 1030. [CrossRef]

2. Zhang, S.C.; Lai, M.N. History and Culture of Chinese Mushroom Cultivation; Shanghai Science \& Technology Publishers: Shanghai, China, 1993; pp. 3-66. ISBN 7-5323-3361-2.

3. Wang, B.; Min, Q.W.; Liu, L.F. Qingyuan Mushroom Culture System, Zhejiang Province; China Agriculture Press: Beijing, China, 2017; pp. 21-32. ISBN 978-7-109-22687-6.

4. Li, W.H. Study on the Protection and Development Strategy of China-NIAHS; Science Press: Beijing, China, 2016; pp. 3-12. ISBN 978-7-03-048259-4.

5. Ministry of Agriculture and Rural Affairs, PRC. A Record of Nationally Important Agricultural Heritage Systems of China. Available online: http://www.moa.gov.cn/ztzl/zywhycsl/ (accessed on 24 June 2014).

6. Min, Q.W. Explanations and Enlightenments of the GIAHS's Criteria. Resour. Sci. 2010, 32, $1022-1025$. (In Chinese)

7. FAO. GIAHS Around the World. Available online: http://www.fao.org/giahs/giahsaroundtheworld/designatedsites/en/ (accessed on 7 December 2018).

8. Li, W.H. Agro-Ecological Farming Systems in China; The Parthenon Publishing Group: New York, NY, USA, 2001; pp. 39-50. ISBN 1-85070-631-x.

9. Liu, S.H.; Jiao, W.J.; Min, Q.W.; Yin, J.Z. The Influences of Production Factors with Profit on Agricultural Heritage Systems: A Case Study of the Rice-Fish System. Sustainability 2017, 9, 1842. [CrossRef]

10. Ye, X.X. Qingyuan Mushroom Cultivation; China Agricultural Science and Technology Press: Beijing, China, 2016; pp. 49-152. ISBN 7-5116-2638-7.

11. Zhang, B.J. Technological Evolution of China Mushroom Cultivation. Edible Fungi 2016, 38, 9. (In Chinese) [CrossRef]

12. Cai, Y.S.; Huang, X.Z. Characteristics of Different Modes for letinula edode Cultivation and Their Combination in Use. Edible Fungi China 2001, 20, 11-12. (In Chinese)

13. Odum, H.T. Environmental Accounting: EMERGY and Environmental Decision Making. Child Dev. 1996, 42, 1187-1201. [CrossRef]

14. Liu, S.H.; Min, Q.W.; Jiao, W.J.; Liu, C.J.; Yin, J.Z. Integrated Emergy and Economic Evaluation of Huzhou Mulberry-Dyke and Fish-Pond Systems. Sustainability 2018, 10, 3860. [CrossRef] 
15. Compilation Committee of Qingyuan County Annals. Qingyuan County Annals; Zhejiang People's Publishing House: Hangzhou, China, 1996; pp. 69-90. ISBN 7-213-01114-6.

16. The Statistical Bureau of Qingyuan County. Statistical Communique of National Economic and Social Development of Qingyuan County 2018. Available online: http://www.zjqy.gov.cn/zjqy/qysj/201904/ t20190425_3721667.html (accessed on 25 April 2019).

17. Zhejiang Provincial Bureau of Statistics, Zhejiang Investigation Team of National Bureau Statistics. Statistical Communique of National Economic and Social Development of Zhejiang Province 2018. Available online: http://tj.zj.gov.cn/art/2019/2/28/art_1525568_30567532.html (accessed on 28 February 2019).

18. National Bureau Statistics. Statistical Communique of National Economic and Social Development 2018. Available online: http://www.stats.gov.cn/tjsj/zxfb/201902/t20190228_1651265.html (accessed on 28 February 2019).

19. Gu, X.G. Analysis and Evaluation on the Sustainable Development of Mulberry-Dyke \& Fish-Pond in Tai Lake Basin: A Case Study of Huzhou. Ph.D. Thesis, Renmin University of China, Beijing, China, 2018.

20. Lan, S.F.; Qin, P.; Lu, H.F. Emergy Analysis of Ecosystem; Chemical Industry Press: Beijing, China, 2002; pp. 167-175. ISBN 7-5025-3835-6.

21. Odum, H.T.; Brown, M.T.; Brandt-Williams, S.L. Handbook of Emergy Evaluation Folio \# 1: Introduction and Global Budget; Center for Environmental Policy, University of Florida: Gainsville, FL, USA, 2000.

22. Brown, M.T.; Protano, G.; Ulgiati, S. Assessing geobiosphere work of generating global reserves of coal, crude oil, and natural gas. Ecol. Model. 2011, 222, 879-887. [CrossRef]

23. Brown, M.T.; Campbell, D.E.; Vilbiss, C.D.; Ulgiati, S. The geobiosphere emergy baseline: A synthesis. Ecol. Model. 2016, 339, 92-95. [CrossRef]

24. Yan, M.C.; Li, H.T.; Cheng, H.; SHEN, W.Q. Emergy Analysis and Assessment of Main Products of Agriculture, Forestry, Animal Husbandry and Fishery in China. J. Beijing For. Univ. Chin. Ed. 2001, 23, 66-69. (In Chinese)

25. Odum, H.T. Environmental Accounting: EMERGY and Environmental Decision Making; John Wiley \& Sons, Inc.: New York, NY, USA, 1996; pp. 290-293. ISBN 0-471-11442-1.

26. Rosa, A.D.L.; Siracusa, G.; Cavallaro, R. Emergy evaluation of Sicilian red orange production. A comparison between organic and conventional farming. J. Clean. Prod. 2008, 16, 1907-1914. [CrossRef]

27. Mao, W. Study on Forestry Ecological and Economic System Substantial Development of Heilongjiang Province Based on Emergy Analysis. Master's Thesis, Northeast Forestry University, Harbin, China, 2008.

28. Lishui Municipal Bureau of Statistics, Lishui Investigation Team of National Bureau Statistics. Lishui Statistical Yearbook 2018; China Statistics Press: Beijing, China, 2018; pp. 41-163. ISBN 978-7-5037-8601-3.

29. Lishui Municipal Bureau of Statistics, Lishui Investigation Team of National Bureau Statistics. Statistical Communique of National Economic and Social Development of Lishui City 2017. Available online: http://tj.lishui.gov.cn/sjjw/tigb/lstjgb/201804/P020190213556800247813.docx (accessed on 3 April 2018).

30. Editorial Board of the Handbook of Agricultural Technology and Economy. Revised Agricultural Technical Economics Manual; Agricultural Press: Beijing, China, 1984; pp. 819-824. ISBN 4144.547.

31. Zhu, Y.L. Study on Agro-Ecosystem's Sustainable Development of Hunan Based on Emergy Theory. Ph.D. Thesis, Central South University of Forestry and Technology, Changsha, China, 2010.

32. Jin, D.; Bian, Z.F. The Accounting of Ecological Cultivation in Xuzhou Based on Emergy and Gross Ecosystem Production. China Land Sci. 2013, 27, 88-94. (In Chinese)

33. Chen, W.; Zhong, S.; Geng, Y.; Chen, Y.H.; Cui, X.W.; Wu, R.; Sun, L.; Tian, X. Emergy based Sustainability Evaluation for Yunnan Province, China. J. Clean. Prod. 2017, 162, 1388-1397. [CrossRef]

34. Zhang, L.X.; Tang, S.; Hao, Y.; Pang, M.Y. Integrated Emergy and Economic Evaluation of a Case Tidal Power Plant in China. J. Clean. Prod. 2018, 182, 38-45. [CrossRef]

35. Corcelli, F.; Ripa, M.; Ulgiati, S. Efficiency and Sustainability Indicators for Papermaking from Virgin Pulp-An Emergy-based Case Study. Resour. Conserv. Recycl. 2018, 131, 313-328. [CrossRef]

36. Jiao, W.J.; Min, Q.W. Reviewing the Progress in the Identification, Conservation and Management of China-Nationally Important Agricultural Heritage Systems (China-NIAHS). Sustainability 2017, 9, 1698. [CrossRef]

(C) 2019 by the authors. Licensee MDPI, Basel, Switzerland. This article is an open access article distributed under the terms and conditions of the Creative Commons Attribution (CC BY) license (http://creativecommons.org/licenses/by/4.0/). 